\title{
DEVELOPMENT OF THE NSW CHILD HEALTH SURVEY
}

\author{
Julianne Quaine," Louisa Jorm and Margaret \\ Williamson \\ Epidemiology and Surveillance Branch \\ NSW Department of Health
}

This article describes the process undertaken by the Epidemiology and Surveillance Branch, as part of the NSW Health Survey Program, to develop the NSW Child Health Survey, which will be conducted in 2001. This survey is planned as the first in a series of tri-annual surveys looking strategically at the health of children aged 0-12 years, and the factors that affect their health and wellbeing.

\section{WHY A SURVEY OF CHILDREN?}

The NSW Department of Health is committed to maximising the health and wellbeing of children in NSW. ${ }^{1}$ Indicators of child health and wellbeing need to be monitored regularly to review the effectiveness of programs and services to improve and maintain children's health, and to identify opportunities for further improvement. There is limited information on the health status of children in NSW.,3 Currently, the main sources of data are collected as a result of contact with health services. However, as the majority of children are healthy and rarely use health services, these data collections do not yield an overall picture of the health of children. ${ }^{4}$ Nor do they provide important information on risk factors linked to the development of disease and ill health later in life. In addition, there is a recognised need to develop and measure the social indicators of health which underpin the wellbeing of children, including measures of the family, and social and economic environments. ${ }^{3-5}$ To date, routine information on these influences on children's health has not been collected. ${ }^{4}$

\section{AIMS AND OBJECTIVES OF THE NSW CHILD HEALTH SURVEY}

The aim of the survey is to report on the health status and wellbeing of children aged 0-12 years resident in NSW. Its objectives are to:

- provide State and Area Health Service-level baseline data on key indicators of children's health and wellbeing, which will allow monitoring of the implementation of the NSW Child Health Policy;

- obtain information on: health risk factors and behaviours; health status; social determinants of health; and use of, access to, and satisfaction with specific health services;

\footnotetext{
Currently with the Population Health Unit, Far West Area Health Service
}

- obtain information relevant to different stages of childhood;

- meet the needs of NSW Area Health Services for information about child health.

\section{SURVEY METHODS}

The survey will be conducted using computer assisted telephone interviews (CATI) of parents or carers of children aged $0-12$ years. The total sample size will be 8,500 , or 500 children in each of the 17 NSW Area Health Services. A two-stage random sampling process will be used: random selection of a household, followed by selection of a child aged 0-12 years in that household. Once the child is selected, the parent or main carer of the child would be identified and interviewed.

\section{Development of the survey instrument}

The child health survey was developed in conjunction with a Child Health Survey Technical Expert Group (CHSTEG). Area Health Services and additional content experts were consulted during the development of content areas and questions. The survey was piloted twice, resulting in a number of modifications to the survey instrument. After modification, the Statewide Health Confidentiality and Ethics Committee approved the questionnaire and survey methods.

\section{Determining the content areas for the survey}

A comprehensive list of possible content areas related to child health was developed through reviewing current child health policy documents (Table 1). A list of 47 issues related to child health was given to members of the CHSTEG,the NSW Health Survey Program Steering Committee, and representatives from the 17 Area Health Services, who were asked to rank each issue as high, medium or low priority for infants $(<1$ year of age), young children (1-4) and older children (5-12). Suggestions for additional content areas were also sought.

Proposed content areas for the survey were narrowed down by applying agreed criteria (listed in Table 2). At the end of this process, 33 content areas were prioritised as 'high'. Questions were developed for the 'high' priority issues only.

\section{Determining questions for specific content areas}

The questions were developed using a number of steps:

- identifying existing surveys;

- identifying possible questions from existing surveys;

- consulting individual members of the CHSTEG or other experts about questions; 


\section{TABLE 1}

\section{NSW CHILD HEALTH SURVEY: CHILD HEALTH POLICY DOCUMENTS USEDTO DETERMINE CONTENT AREAS}

- The Health of Young Australians: a national health policy for children and young people, 1995

- Health Goals and Targets for Australian Children and Youth, 1992

- The National Health Plan for Young Australians, 1996

- Caring for Health, Caring for Children: a discussion paper towards the development of a child health policy for NSW, 1996

- The Start of Good Health: the health of children in NSW, 1998 (draft).

\section{TABLE 2}

\section{NSW CHILD HEALTH SURVEY: CRITERIA FOR} SELECTION OF CONTENT AREAS

1. Priority for child health as documented in a state or national child health policy document

2. Meets the information needs of the NSW Department of Health and Area Health Services in relation to child health

3. Information not readily available from other sources

4. Estimated sample size is large enough to provide data that can be used to generalise responses to the NSW population of children

5. Not highly sensitive to respondents and likely to cause failure to complete the survey.

- modifying existing questions where existing questions were not suitable;

- developing new questions where questions did not exist;

- presenting the proposed questions to CHSTEG for endorsement;

- piloting the draft questions.

The proposed questions, original questions and source, and information that would be derived from the question, were documented for each content area.

Overall, 40 surveys were reviewed (with 38 of these yielding suitable questions), 32 people were consulted about questions for specific content areas and 352 questions were proposed to the CHSTEG.

The proposed questions were reviewed to ensure that they:

- addressed important health indicators for the specific content area;

\section{TABLE 3}

NSW CHILD HEALTH SURVEY: CONTENT AREAS OF QUESTIONS, BY AGE GROUP

\begin{tabular}{|c|c|c|c|}
\hline \multirow{2}{*}{ CONTENT AREA } & \multicolumn{3}{|c|}{ AGE GROUP (years) } \\
\hline & $0-<2$ & $2-4$ & $5-12$ \\
\hline \multicolumn{4}{|l|}{ Health service use: } \\
\hline early childhood health centres & $\checkmark$ & $\checkmark$ & \\
\hline Health service use: & & & \\
\hline visits to general practitioners & $\checkmark$ & $\checkmark$ & $\checkmark$ \\
\hline Health service use: & & & \\
\hline in last 12 months & $\checkmark$ & $\checkmark$ & $\checkmark$ \\
\hline \multicolumn{4}{|l|}{ Health service use: } \\
\hline Personal Health Record & $\checkmark$ & $\checkmark$ & $\checkmark$ \\
\hline Folate & $\checkmark$ & & \\
\hline Sleeping position & $\checkmark$ & & \\
\hline Breastfeeding & $\checkmark$ & & \\
\hline Nutrition & & $\checkmark$ & $\checkmark$ \\
\hline Food security and hunger & $\checkmark$ & $\checkmark$ & $\checkmark$ \\
\hline Immunisation & $\checkmark$ & $\checkmark$ & \\
\hline Asthma & & $\checkmark$ & $\checkmark$ \\
\hline Dental health & $\checkmark$ & $\checkmark$ & $\checkmark$ \\
\hline Health Status (CHQ) & & & $\checkmark$ \\
\hline Respondent's health & & & $\checkmark$ \\
\hline $\begin{array}{l}\text { Emotional and behavioural problems } \\
\text { Health services: }\end{array}$ & & $\checkmark$ & $\checkmark$ \\
\hline infant behavioural problems & $\checkmark$ & & \\
\hline Home visiting & $\checkmark$ & $\checkmark$ & \\
\hline Parental support services & & $\checkmark$ & $\checkmark$ \\
\hline Sun exposure & $\checkmark$ & $\checkmark$ & $\checkmark$ \\
\hline Disability: sight & & $\checkmark$ & $\checkmark$ \\
\hline Disability: hearing & $\checkmark$ & $\checkmark$ & $\checkmark$ \\
\hline Disability: speech & & $\checkmark$ & $\checkmark$ \\
\hline Family functioning & $\checkmark$ & $\checkmark$ & $\checkmark$ \\
\hline Social support & $\checkmark$ & $\checkmark$ & $\checkmark$ \\
\hline Social capital & $\checkmark$ & $\checkmark$ & $\checkmark$ \\
\hline Injury: drowning & $\checkmark$ & $\checkmark$ & $\checkmark$ \\
\hline Injury: sports & & & $\checkmark$ \\
\hline Video-TV watching & & & $\checkmark$ \\
\hline School attendance & & $\checkmark$ & $\checkmark$ \\
\hline Preschool attendance & & $\checkmark$ & \\
\hline Child care attendance & $\checkmark$ & $\checkmark$ & \\
\hline Parents-others smoking in home & $\checkmark$ & $\checkmark$ & $\checkmark$ \\
\hline Mother smoking in pregnancy & $\checkmark$ & & \\
\hline Demography & $\checkmark$ & $\checkmark$ & $\checkmark$ \\
\hline
\end{tabular}

- were suitable for telephone administration;

- were suitable for delivery to proxy respondents.

The proposed questions for each high priority content area were considered by the CHSTEG and accepted, modified or rejected. At this stage, some content areas were excluded from the survey as suitable questions could not be identified. 


\section{THE FINAL SURVEY INSTRUMENT}

The final survey instrument consists of 285 questions covering 34 content areas. These are shown in Table 3. The survey includes 63 new questions, while the remainder are modified or adopted from previous surveys.

\section{CONCLUSION}

The NSW Child Health Survey will provide essential data on the health status of children in NSW. The process of survey development, overseen by a technical expert group, proved highly successful, resulting in an innovative survey instrument that addresses both established and emerging priority areas in child health. The survey will be conducted in 2001, and we eagerly await the outcome.

\section{REFERENCES}

1. NSW Department Health. The Start of Good Health: Improving the Health of Children in NSW. Sydney: NSW Department of Health, publication number HSP 980130, 1999.

2. Jorm L. Surveillance of child health in NSW: status, gaps and developments. NSW Public Health Bulletin 1998; (9): 73-75.

3. Commonwealth Department of Human Services and Health. The health of young Australians: a national health policy for children and young people. Canberra: AGPS, 1995.

4. Moon L, Rahman N, Bhatia K. Australia's children: their health and wellbeing 1998. Canberra: Australian Institute of Health and Welfare, 1998.

5. Nossar V, Alperstein G. Monitoring child health (editorial). NSW Public Health Bulletin 1998; (9): 71-72. w

\section{PROGRESS ON FAMILIES FIRST: A SUPPORT NETWORK FOR FAMILIES RAISING CHILDREN}

\section{Dianne Hudson}

Program Manager, Families First

Office of Children and Young People

Research shows that significant improvements in a child's health, education and welfare can be sustained when early intervention and support services are provided. ${ }^{1,2,3}$ This article describes Families First, a strategy sponsored by the NSW Government to re-shape and develop prevention and early intervention services, which help parents and communities sustain their children's health and wellbeing in the long term.

\section{INTRODUCTION}

Families First is the joint responsibility of Area Health Services, the Departments of Ageing and Disability, Community Services, Education and Training, Health and Housing. Non-government services funded by the NSW Government are also participating.

What follows is a snapshot of how Families First is unfolding in the first group of areas: the Mid North Coast, Far North Coast and South Western Sydney within existing resources and with additional funding of \$3.64 million in 1999-2000. Implementation in these areas started at the end of 1998.

\section{SERVICES UNDER FAMILIES FIRST}

The agencies responsible for Families First are now jointly planning and making decisions together about the direction of Families First within their areas. Changes are being made to how some services support families, other services are being strengthened, and new services are starting around the four fields of activity outlined below.

Supporting parents who are expecting or caring for a new baby

Maternal and child health services have an important role in supporting parents through pregnancy and following the birth of their children. Under Families First, and in line with the Start of Good Health: Improving the Health of Children in NSW (1999), ${ }^{3}$ the focus is to provide accessible healthcare, support and information about parenting. We also want to link parents to other services as soon as possible if there are signs that they are in need of additional support.

\section{Antenatal Care}

Some women, particularly Aboriginal and young women, have difficulty accessing antenatal care and support. To aid these women, we are increasing support during pregnancy by reaching out to them and providing services at home-and in other community settings-where they are more likely to access services.

For example, a new service called the Young Parents Program started in August 1999 in Kempsey. Many pregnant teenagers do not attend the antenatal care clinic at Kempsey Hospital because they don't feel comfortable in this environment. Through Families First, an alternative 